\title{
Freire, André (2014), Austeridade, democracia e autoritarismo
}

Pablo Almada

\section{OpenEdition}

1 Journals

Edição electrónica

URL: http://journals.openedition.org/rccs/6165

DOI: $10.4000 /$ rccs.6165

ISSN: 2182-7435

Editora

Centro de Estudos Sociais da Universidade de Coimbra

\section{Edição impressa}

Data de publição: 1 dezembro 2015

Paginação: 177-180

ISSN: 0254-1106

\section{Refêrencia eletrónica}

Pablo Almada, «Freire, André (2014), Austeridade, democracia e autoritarismo », Revista Crítica de Ciências Sociais [Online], 108 | 2015, posto online no dia 16 dezembro 2015, consultado o 23 setembro 2020. URL : http://journals.openedition.org/rccs/6165; DOI : https://doi.org/10.4000/rccs.6165 


\section{Recensões}

\section{López de la Vieja, Maria Teresa (org.) (2014), Bioética en plural. Madrid: Plaza y Valdés Editores, 350 pp.}

Bioética en plural é uma obra coletiva organizada por Maria Teresa López de la Vieja e inclui diversos estudos, abordando diferentes aspetos daquela que é a "mais radicalmente contemporânea das disciplinas" (p.7), a bioética. Professora catedrática de Filosofia Moral na Universidade de Salamanca, Maria Teresa López de la Vieja é autora de várias obras sobre estas temáticas, das quais se destacam: Princípios morales y casos prácticos (2000), Ética y literatura (2003), La mitad del mundo. Ética y crítica feminista (2004), Bioética y ciudadania (2008), La pendiente resbaladiza (2010) e Bioética y literatura (2013).

Bioética en plural é constituída por uma apresentação seguida de três partes: "I-Bioética. Figuras, instituciones"; "II-La salud y la vida" e "III - Bibliografía". A Parte I é constituída por um conjunto de quatro estudos. O primeiro, de Stuart J. Youngner, analisa os diferentes papéis que um especialista em bioética pode desempenhar e os vários conflitos daí decorrentes. Depois de clarificar a definição de cada um desses papéis - erudito, ativista e político - o autor faz o inventário de alguns dos possíveis "choques", pois há normas específicas inerentes a cada um deles que podem, por vezes, colidir.

No segundo e no quarto estudo, o tema em debate incide na questão dos Conselhos de Ética a partir das reflexões de Maria Teresa López de la Vieja e de Maria Fernanda Henriques.

A partir do relato da experiência pessoal do ator britânico Dirk Bogarde, relacionada com os seus problemas de saúde e com as suas convicções sobre a eutanásia, Maria Teresa López de la Vieja sugere um conjunto de indicações sobre como deverá ser a constituição de um Conselho de Ética. Recorre à tipologia de Max Weber para a atividade política e, aplicando-a à área da bioética, distingue os participantes em vários tipos: profissionais, semiprofissionais e ocasionais. A autora defende que um comité de ética não pode ser entendido como mera agregação de várias contribuições individuais, mas antes como um espaço intersubjetivo de deliberação prática, incluindo especialistas e não especialistas. Neste sentido, sublinha a relevância da presença de especialistas em filosofia pela sua familiaridade com a prática da argumentação. Competências como análise crítica, confronto de diferentes teorias e argumentos, interpretação e mediação são decisivas nos processos de deliberação inerentes aos comités de ética.

No seu trabalho "La Bioética en Portugal: perspectivas", realizado com a colaboração de Paula Martinho da Silva, Maria Fernanda Henriques situa o início da reflexão bioética em Portugal na década de 1980, um começo que, embora tardio, esteve ligado ao Centro de Estudos de Bioética em Coimbra, cuja atividade se desenvolve a partir de 1988. O artigo dá conta, de uma forma pormenorizada, desses desenvolvimentos nos vários planos, e destaca a constituição em 1990 do Conselho Nacional de Ética para as Ciências da Vida (CNECV), considerando que este representa uma viragem significativa na reflexão bioética em Portugal. $\mathrm{Na}$ análise que realiza, Maria Fernanda Henriques 
observa que a reflexão sobre a ética e a bioética é escassa na sociedade portuguesa, o que também se refletiu no funcionamento interno do CNECV. Entre as várias razões explicativas é apontada a fragilidade do espaço público em Portugal, o que suscita alguns receios relativamente ao futuro da bioética no nosso país.

Ainda na Parte I da obra é incluído o estudo de Ion Arrieta Valadero sobre o funcionamento do princípio de autonomia em bioética. Reportando-se à polémica entre Gerald Dowrkin e Onora O'Neill sobre a autonomia na sua relação com a confiança, o autor analisa algumas das diferentes perspetivas em confronto: autonomia pessoal, autonomia moral (de princípios), autonomia relacional e autonomia naturalizada (corporizada) e a sua incidência na ética assistencial e na ética da investigação biomédica.

A Parte II da obra "La salud y la vida" é constituída por um conjunto de cinco estudos dedicados a questões mais específicas no domínio da bioética, como sejam a doação de órgãos, as políticas de transplante ou o aborto.

David Rodriguez-Arias analisa as políticas de transplante, os meios e as carências existentes, assim como a perceção social acerca dos mesmos. Constata-se que a escassez de órgãos é, hoje, uma dificuldade, e que as várias estratégias para a enfrentar devem ser sujeitas a discussão, pois embora a sua finalidade seja salvar vidas, não deixam de colocar inúmeros problemas éticos. Na verdade, os maiores obstáculos que se colocam relativamente à disponibilidade de órgãos são mais de carácter ético e social do que propriamente técnico. Rodriguez-Arias analisa essa problemática nas suas diferentes dimensões e sugere algumas estratégias que podem ser: incentivos económicos, tomadas de posição relativas à determinação do final da vida, processo de consentimento para a extração, sistema de distribuição de órgãos extraídos, critérios para determinar quem pode ser dador. Rosana Triviño Caballero dedica o seu artigo à análise de legislação, concretamente o Real Decreto-lei 16/2012. A aplicação desta lei tem, entre os seus efeitos, um que conduz à segregação da população, pois nega a assistência médica a um grupo (imigrantes ilegais) com base na sua situação administrativa. Na perspetiva da autora, esta disposição põe em causa o direito básico à assistência na saúde, sendo, por isso, expressão de um retrocesso social em Espanha.

Lizbeth Sagols parte da análise da perspetiva da ecofeminista Val Plumwood sobre a opressão de género e da natureza, no seu confronto com a teoria crítica do patriarcado, para tentar mostrar como as questões de género e a destruição da natureza se enraízam numa visão dualista que caracterizou a cultura patriarcal. $\mathrm{Na}$ perspetiva desta teoria, o patriarcado não é exclusivamente ocidental e é anterior ao colonialismo. Nas considerações finais do seu artigo, Lizbeth Sagols chama a atenção para o facto de que, não ignorando o peso do colonialismo, será importante sublinhar que o extermínio da natureza resulta de uma conceção hierárquica/ /inferiorizante que separa o ser humano dos outros seres, considerados mais débeis. Neste sentido, propõe a aprendizagem de uma outra forma de relacionamento entre os seres humanos e destes com a natureza. O que passará por nos compreendermos como seres de relação, seres que, em liberdade, constroem uma igualdade básica. Significa isto que deveria emergir uma nova identidade ética, sustentando-se no cuidado e na responsabilidade face a todos os seres vivos, entendidos todos como portadores de interesses e necessidades e dignos de atenção e de respeito.

No último estudo da parte II, "Los grados del vivir", da autoria de Lorenzo Peña y 
Txetxu Ausín, é apresentada uma perspetiva sobre a vida (e o seu surgir) considerando-a como um continuum, algo que se desenvolve por estádios. Assim, e tendo em consideração o valor da vida humana que é hoje consensualmente admitido, a questão debatida refere-se à licitude do aborto. O que está em causa é a determinação de um momento que possa ser considerado como "fronteira", ou seja, estabelecer um momento em que não existiria ainda vida humana e o momento em que esta já existisse. Na sequência da exposição de diferentes respostas, os autores do artigo sugerem uma proposta gradualista, baseada no seguinte princípio: "Em cada novo passo, é maior o seu grau de existência e menor o da não existência" (p. 254). A partir desta perspetiva, analisam a interrupção da gravidez segundo graus de legitimidade e ilegitimidade e dos diferentes direitos que podem estar em conflito.

Por último, na Parte III, Alberto Molina Perez faculta uma extensa bibliografia sobre temas de bioética, editadas em língua castelhana entre 2005 e 2013. Este conjunto de referências bibliográficas constitui um bom instrumento de trabalho para todos/as os/as investigadores/ /as nesta área, sendo um dos aspetos mais significativos da obra.

Pelo exposto parece-me ser possível concluir que estamos perante uma obra de grande utilidade para quem trabalha em bioética, mas também para os/as investigadores/as das diferentes áreas disciplinares que se entrecruzam nesta reflexão. De igual modo, o seu interesse deve estender-se ao público em geral, dado que os temas tratados nos vários artigos dizem respeito a qualquer pessoa que já se encontre ou potencialmente possa vir a encontrar-se afetada por este tipo de decisões. Na verdade, as questões da saúde e da doença, da vida e da morte são questões a que nenhum ser humano pode ficar indiferente. As inúmeras possibilidades técnicas que hoje se colocam e, em simultâneo, os inúmeros riscos, exigem de cada um de nós informação, reflexão e participação. O pluralismo e a diversidade, características da sociedade contemporânea, são também características da bioética, e constituem-se, igualmente, como o distintivo desta obra e como justificativo do título Bioética en plural. Contudo, Maria Teresa López de la Vieja não deixa de lembrar que, a partir do diálogo entre as diferentes perspetivas a que a obra dá voz, se podem estabelecer pontes. A diversidade não é para separar, para atomizar, mas para articular. A racionalidade é um espaço de conflitualidade e de controvérsia, sendo na vivacidade do debate que podemos encontrar novas possibilidades. Penso ser esta a grande lição que fica para quem lê Bioética en plural.

Maria do Céu Pires

\section{Freire, Andre (2014), Austeridade, democracia e autoritarismo. Lisboa: Nova Vega, $152 \mathrm{pp}$.}

Compreender a complexidade do sistema político português, em um momento de crise econômica e política, é o desafio proposto pelo cientista político André Freire nesta obra. Professor do ISCTE-IUL e investigador do CIES-IUL, Freire tem como seu objeto de estudo os temas de comportamento político, sistemas eleitorais, representação e instituições políticas, participando amplamente nos 
debates públicos e políticos de Portugal. Austeridade, democracia e autoritarismo é uma compilação de vários artigos publicados entre 2007 e 2014, em sua coluna do jornal Público. A obra apresenta uma visão crítica sobre os dilemas concernentes ao sistema político e aos partidos, além do questionamento do futuro da democracia portuguesa e europeia.

Os artigos apresentados confluem com momentos-chave de conjuntura, enfatizando os efeitos do neoliberalismo e da governação "austeritária" na política partidária, na democracia, na vida concreta dos cidadãos e os desafios políticos para a Europa. O argumento central da obra parte do entendimento de que a condução do sistema político português enfrenta uma crise de governabilidade - fator que oferece um olhar ampliado sobre os desafios dos partidos políticos e da esquerda, frente aos cortes orçamentários nas políticas sociais e aos resultados diretos na educação, na saúde e no trabalho. Essa percepção indica que, para que sejam superados os problemas estruturais do sistema político e da conjuntura específica, seria necessária uma articulação de fatores internos (crítica da governabilidade austeritária, rearticulação das esquerdas, reforma política) com fatores externos (democracia europeia). Sua visão destrincha os meandros de uma alternativa política concreta e de oposição à atual conjuntura econômica e política, o que o autor faz de forma coerente e exemplar. No primeiro momento da obra ("A democracia sob o fogo da Troika e da governação austeritária"), Freire analisa como a crise econômica recente conduziu a uma grave crise na democracia portuguesa. Tomando como eixo o "bloqueamento do sistema político" (p. 20), as políticas seguidas pelo Partido Social Democrata (PSD, no governo desde 2009) tiveram uma articulação aos ajustes econômicos impostos pela Troika, medidas que não foram sufragadas eleitoralmente. A aceitação do programa das instituições financeiras implicou na sistemática liberalização do Estado e seu recuo nas áreas sociais, além do controle das relações de trabalho e aumento do desemprego, sobretudo das camadas mais jovens e qualificadas da população. A governabilidade exercida pelo PSD, de caráter "ultraliberal", encontrou campo aberto pelo legado do Partido Socialista (PS), que nos últimos anos de governo empreendeu medidas de liberalização que o aproximou da direita.

O segundo conjunto de artigos ("Política de alianças e dimensões de conflito: dilemas das esquerdas") procura apresentar os fatores que conduziram a uma crise das esquerdas portuguesas. Seguindo uma tipologia analítica da esquerda - Freire, André; March, Luke (2012), A esquerda radical em Portugal e na Europa: Marxismo, mainstream ou marginalidade? Porto: Quidnovi - Freire aponta que parte dos problemas referentes à governabilidade austeritária tiveram origem nas dificuldades da esquerda portuguesa em se afirmar como oposição. Os motivos seriam a pendência do sistema eleitoral português à direita, o "centrismo" do PS e seu alinhamento com a direita, a impossibilidade de alianças entre as esquerdas e sua desradicalização. Esses fatores geraram um entrave eleitoral, onde as esquerdas perderam seus votos nas últimas eleições (especialmente nas autárquicas). Nesses meandros, o ensaio de outras alternativas, como as "listas de cidadãos" para as disputas autárquicas merecem destaque. Mesmo assim, coloca-se o desafio às esquerdas (PS, Bloco de Esquerda e Partido Comunista Português) em efetivar alianças.

A análise do sistema eleitoral português é o tema da terceira parte ("Os portugueses, a política e a sua reforma"). Freire inicia o debate refletindo sobre os resultados 
do estudo sobre o sistema eleitoral e as possibilidades de reforma - Freire, André; Meirinho, Manuel; Moreira, Diogo, (2008), Para uma melhoria da representação política. A reforma do sistema eleitoral. Lisboa: Sextante. Ao analisar os modelos dos outros sistemas políticos europeus, constata-se que, em Portugal, há um problema na qualidade da representação, por constituir um sistema de "listas fechadas e bloqueadas, conjugadas com um único segmento" (p. 79). Perante esse diagnóstico, propõe a "representação proporcional de múltiplos segmentos”, que fortaleceria a aproximação entre eleitos e eleitores, além de manter os níveis de proporcionalidade e governabilidade. Para isso, Freire apresenta duas propostas que permitiriam a revalorização do sistema político: uma "moção de censura construtiva" (um governo somente poderia cair caso houvesse uma proposta alternativa, reforçando a estabilidade de governos minoritários); e a permissão para "coligação de listas" em nível nacional (permitindo a cooperação entre listas e conversão de votos em mandatos). Se o atual sistema dificulta a personalização dos votos, por conta das listas fechadas, há uma defesa do "voto preferencial" para aproximar o eleitor de seus eleitos. A alternativa proposta é a de um sistema misto, com círculos uninominais e plurinominais, e, um círculo nacional, que, conjuntamente, resolveriam os problemas de proporcionalidade. A reforma eleitoral teria, segundo o autor, o objetivo de aproximar os portugueses de seus representantes e exigir uma mudança de atitude, além de reforçar a governabilidade.

No último excerto ("A Europa e a política internacional") são debatidos os desafios atuais da Europa (o modelo social, a política externa e a democracia), bem como a crise neoliberal (e suas alternativas) e o esfacelamento da "ideia" de Europa. Os argumentos questionam se a ideia de coesão social e política, encabeçadas pela integração social, pela regulação do mercado e por uma política social-democrata não estaria sendo sufocada pela crise do neoliberalismo dos últimos anos. Constata-se que a autonomia do sistema financeiro, que subordina as esferas sociais e políticas em prol da desregulação capitalista, tem se constituído problema fundamental da coesão europeia. Para o controle do capitalismo financeiro, uma repactuação do modelo de Estado pode ser oferecida como alternativa ao neoliberalismo. Porém, velhos problemas que ganharam nova roupagem também devem ser repensados: a possibilidade de Estados multinacionais, o respeito pela ordem política internacional, o separatismo e a religião na esfera pública.

Ao longo de Austeridade, democracia e autoritarismo, uma visão bastante lúcida da realidade política portuguesa e europeia é apresentada, procurando caminhos para a renovação. As alternativas passam por atribuir um novo papel para as esquerdas, as quais são prudentemente criticadas de forma construtiva. Resta saber quais as articulações possíveis entre democracia representativa e democracia participativa, algo que escapa da análise do autor. A reforma do sistema eleitoral ganha grande enfoque, mas coloca em dúvida se, ao serem aplicadas formulações eleitorais semelhantes às de outros países (sobretudo dos países nórdicos), seria possível dar conta de tal lacuna. O incentivo representativo é válido, mas deve ser considerada a especificidade de anos de ausência de participação política, uma herança dos anos de autoritarismo salazarista. Notadamente, o autoritarismo neoliberal é de uma nova roupagem, no que tange ao controle do Estado sobre a sociedade civil, mas compartilha da premissa econômica de que a defesa de um modelo de desenvolvimento (no Estado Novo, o colonialismo; 
na democracia contemporânea, o neoliberalismo austeritário) deve ser seguido sem a necessidade de legitimação eleitoral. Essa prática aumenta os riscos para as sociedades do Sul da Europa, que se colocam à margem do modelo europeísta do centro. Assim, as instâncias representativas ficam cada vez mais reféns de despolitização e do afastamento político, como aponta Freire. Mas o desafio é suprir essa lacuna, fato que se pode orientar por outros dois caminhos: um debate comparativo do presente e do passado, procurando identificar os problemas políticos que persistem (domínio das oligarquias e elites políticas, alijamento das classes trabalhadoras e populares, de jovens e imigrantes na participação política, etc.); e a presença de uma sociologia e ciência política "pública", de intervenção e engajamento - fato que a presente obra cumpre com rigor. Não há dúvida de que se trata de uma grande reflexão, de leitura obrigatória quando o assunto é a busca de alternativas políticas.

Pablo Almada

\section{Namorado, Rui (2013), O mistério do cooperativismo. Da cooperação ao movimento cooperativo. Coimbra: Edições Almedina, 165 pp.}

Noção relativamente recente, a economia social é hoje em dia um assunto cada vez mais destacado. Em França, a primeira lei-quadro da economia social e solidária foi assim aprovada em julho de 2014 . Em Portugal, podemos referir as ações realizadas pela Cooperativa António Sérgio pela Economia Social (CASES) e a Lei de Bases de 2013. Mas o recurso a essa noção não se acompanhou sempre de uma clarificação da sua definição e alimenta uma certa confusão. O livro mais recente de Rui Namorado, focado na questão do cooperativismo, pilar elementar da economia social, visa restituir as suas raízes e as suas origens a um movimento que se caracteriza pela sua oposição ao sistema de produção capitalista.

Em O mistério do cooperativismo, Rui Namorado procura dar visibilidade ao processo de constituição do fenómeno das cooperativas e das suas relações com os movimentos operário e socialista. $\mathrm{O}$ autor esclarece esses relacionamentos com as noções de galáxia cooperativista, ligada ao movimento operário e componente do conjunto da economia social. Segundo o autor, "dificilmente se estudará com fecundidade o fenómeno cooperativo em toda a sua amplitude, esquecendo a origem do movimento através do qual ele se exprimiu" (p. 32). O uso e abuso da noção de economia social torna visível um esquecimento das raízes do movimento cooperativo e nomeadamente a sua carga política de procura de alternativas à exploração. Contra o potencial apagamento dessa história, Rui Namorado desenvolve um trabalho que tem como objetivo tornar visível a genealogia das cooperativas ainda ativas hoje em dia. Embora a fundação da Sociedade dos Pioneiros de Rochdale, em 1844, constituísse uma marca consensual do cooperativismo e dos seus princípios, trata-se de um movimento mais antigo e o autor define a cooperação como base de cada sociedade. A expansão do sistema de economia capitalista vem trazer durante o século XIX um agravamento da pobreza e da exploração. Se bem que o movimento secular da cooperação encontra uma forma jurídica nova com a criação de cooperativas de produção e de consumo. Nascido para contestar as consequências do capitalismo, o cooperativismo partilha 
essa origem com o movimento operário e as doutrinas socialistas que veem a luz nesse mesmo século. $\mathrm{O}$ estudo desse relacionamento do movimento cooperativo com as organizações operárias é uma das vertentes principais desse livro. Essas ligações não foram sempre uniformes mas deixaram marcas profundas no movimento cooperativo.

Posta em causa pelo capitalismo, a divisão social do trabalho e a lógica de lucro, a cooperação e a solidariedade tomam expressão com as reivindicações do movimento operário. As cooperativas aparecem, assim, como uma fonte de procura de alternativas ao desenvolvimento do capitalismo como sistema hegemónico. Com o proletariado a crescer, fruto da generalização do modo de produção capitalista, o movimento operário organiza-se, tendo como base o desenvolvimento das doutrinas socialistas. O continente europeu, espaço de realização da revolução industrial, constituiu assim a matriz original do cooperativismo enquanto movimento. Rui Namorado desenvolve uma interessante análise do relacionamento das sucessivas Internacionais de trabalhadores com o assunto do cooperativismo. A criação da Associação Cooperativa Internacional em 1895 permite enquadrar de forma geral os movimentos cooperativos nacionais. No entanto, o autor mostra que a relação das cooperativas e do movimento operário à qual pertence está longe de ser estável. Enquanto alguns líderes operários veem nas cooperativas um desvio da luta contra o capitalismo e um enfraquecimento da classe operária, outros, como Jean Jaurès, definem as cooperativas como uma fonte de alternativas ao modo capitalista e um pilar do movimento operário, ao lado do partido e do sindicato. Rui Namorado defende então a ideia de que, embora as cooperativas possam crescer fora dos meios operários, elas são parte essencial do movimento operário pela sua resistência prática e quotidiana à lógica capitalista (nomeadamente com a ausência de lucro). No entanto, o estudo histórico mostra um movimento cooperativo em tensão entre dois polos: uma ligação forte com as doutrinas socialistas e a procura de alternativas; e o seu empreendedorismo inserido num contexto capitalista. Através das cooperativas, é o debate entre revolução e reforma que se replica.

O capítulo IV apresenta um rico resumo dos desenvolvimentos do movimento cooperativo do século XIX até à Primeira Guerra Mundial em seis países: Inglaterra, França, Bélgica, Itália, Alemanha e Portugal. Este estudo histórico permite destacar a complexidade das ligações do movimento cooperativo com as organizações operárias, bem como as diferenças nacionais. Se na Inglaterra e em França as cooperativas se enquadram na área operária e socialista, elas mostram uma relativa autonomia na Alemanha, onde as cooperativas não operárias têm um peso maior. Na Bélgica e em Itália o papel dos sindicatos revelou-se importante, bem como o envolvimento dos católicos sociais. Em Portugal, o crescimento das ideias socialistas na década 70 do século XIX abriu um espaço para o desenvolvimento do cooperativismo no país.

O autor volta depois, aos desenvolvimentos do cooperativismo depois da Primeira Guerra Mundial e sobretudo depois de 1917, data da Revolução Russa. Na União Soviética, as cooperativas tinham uma natureza instrumental, não permitindo um controlo democrático real. Com a emergência do Terceiro Mundo, a temática das cooperativas insere-se na problemática do desenvolvimento. A economia social representa um novo momento de investimento nas cooperativas como estruturas portadoras de um potencial inovador. Rui Namorado propõe a imagem esclarecedora da galáxia cooperativa como interseção da 
constelação do movimento operário e da economia social. Pertencendo a estes dois espaços, o cooperativismo adquire assim a sua natureza própria feita dessa simbiose. Com a queda do modelo coletivista de Estado incarnado pela União Soviética, o sistema capitalista apareceu para muitos como o único horizonte possível. ${ }^{1}$ As cooperativas, frutos das convergências entre a prática secular de cooperação e da influência do movimento operário, vêm lembrar como uma outra organização económica é possível e que a procura de alternativas permanece como uma tarefa atual. Aplicando-se à cooperação em vez da competição, as estruturas cooperativas representam um desafio ao sistema capitalista de organização das nossas sociedades. O livro do Rui Namorado permite destacar a natureza própria do fenómeno cooperativo, fenómeno imbricado com o desenvolvimento do movimento operário. Segundo a CASES, cooperativa de interesse público, existiam em 2010 mais de 3100 cooperativas em Portugal. Esta categoria, bem como a própria noção de economia social, aparecem muitas vezes como imprecisas, colocando lado a lado estruturas que pouco têm a ver. Pode ser difícil, assim, ver o que partilham uma cooperativa de produção operária ou uma associação popular com uma Misericórdia ou uma empresa clássica que investe na inovação social. No contexto de crise atual, cada discurso divulgado torna a economia social em mais uma oportunidade de emprego, nomeadamente para “jovens empreendedores”. A especificidade das cooperativas como dinâmica alternativa à capitalista corre o perigo de ser banalizada e afogada no meio destes discursos. O livro de Rui Namorado é uma obra essencial, que vem sublinhar os fundamentos da cooperação como movimento social, potenciador de emancipação humana.

Pierre Marie

\section{Maria do Céu Pires}

Instituto de Investigação e Formação Avançada (IIFA), Universidade de Évora Palácio do Vimioso, Largo Marquês de Marialva, Apartado 94, 7002 - 554 Évora, Portugal Contacto: ceupires@gmail.com

\section{Pablo Almada}

Departamento de Ciências Sociais, Universidade Estadual de Londrina (UEL), Rodovia Celso Garcia Cid, PR-445, Km-380, Campus Universitário, 86057-970, Londrina, Paraná, Brasil

Contacto: pabloera@gmail.com

\section{Pierre Marie}

Faculdade de Letras da Universidade de Coimbra Largo da Porta Férrea, 3004-530 Coimbra, Portugal Contacto: pierregmarie@gmail.com

\footnotetext{
${ }^{1}$ Podemos aqui referir o livro de Francis Fukuyama (1992), O fim da bistória e o último bomem. Lisboa: Gradiva.
} 